\title{
Synthesis and Properties
}

\section{of Biodegradable Copolymers Based \\ on $\varepsilon$-Caprolactam and $\alpha$-Angelicalactone}

\author{
Konstantin L. Kaygorodov, Valery E. Tarabanko*, \\ Andrei A. Morozov and Marina A. Smirnova \\ Institute of Chemistry and Chemical Technology SB RAS \\ FRC "Krasnoyarsk Science Center SB RAS" \\ 50/24 Akademgorodok, Krasnoyarsk, 660036, Russia
}

Received 29.10.2019, received in revised form 30.10.2019, accepted 17.11.2019

Copolymers and block-copolymers of $\varepsilon$-caprolactam, $\alpha$-angelicalactone and polyangelicalactone were first synthesized by the anionic polymerization method. Yields of polymers and rates of their formation decrease with increasing the $\alpha$-angelicalactone and polyangelicalactone concentration. Physical and mechanical properties of the obtained copolymers are very close to the properties of polycaprolactam. The synthesized block-copolymers are biodegradable in the grey forest soil, and they are completely visually destroyed during 20 weeks. The water extracts of the biodegradation products are nontoxic.

Keywords: caprolactam, angelicalactone, polyangelicalactone, polycaprolactam, biodegradation, copolymers.

Citation: Kaygorodov K.L., Tarabanko V.E., Morozov A.A., Smirnova M.A. Synthesis and properties of biodegradable copolymers based on $\varepsilon$-caprolactam and $\alpha$-angelicalactone, J. Sib. Fed. Univ. Chem., 2019, 12(4), 503-511. DOI: 10.17516/19982836-0146.

(c) Siberian Federal University. All rights reserved

* Corresponding author E-mail address: veta@icct.ru 


\title{
Синтез и свойства биодеградируемых \\ сополимеров на основе в-капролактама \\ и ф-ангеликалактона
}

\begin{abstract}
К.Л. Кайгородов, В.Е. Тарабанько, А.А. Морозов, М.А. Смирнова

Институт химии и химической технологии СО РАН ФИЦ «Красноярский научный центр СО РАН» Россия, 660036, Красноярск, Академгородок, 50/24
\end{abstract}

Впервые методом анионной полимеризации синтезированы сополимеры и блок-сополимеры

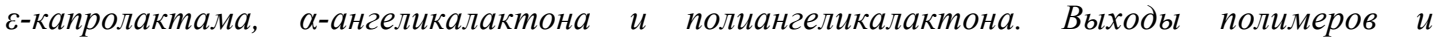
скорости полимеризаџии снижаются при увеличении концентрации а-ангеликалактона u полиангеликалактона. Полученные сополимеры имеют физико-механические свойства, близкие к таковым для поликапролактама. Синтезированные блок-сополимеры в отличие от гомополимера поддаются биодеградаџии, т.е. визуально полностью разрушаются в серой лесной почве в течение 20 недель. Водные вытяжки продуктов биодеградации не обладают токсическими свойствами.

Ключевые слова: капролактам, ангеликалактон, полиангеликалактон, поликапролактам, биодеградация, сополимерь.

Поли-є-капроамид (капрон, найлон-6, ПКА), обладая большим набором ценных свойств, является одним из основных конструкционных пластиков в машиностроении, а также широко используется при производстве волокон различного назначения и медицинских изделий [1]. Полиэфирамиды на основе ПКА находят все более широкое применение в областях, где востребованы биоразлагаемые пластики с высокими эксплуатационными характеристиками [2].

Получаемый из возобновляемого сырья $\alpha$-ангеликалактон (5-метил-2(3Н)-фуранон, $\alpha$ АЛ) способен путем анионной полимеризации образовывать биоразлагаемый непредельный полиэфир - полиангеликалактон (ПАЛ) [3-8] (рис. 1).

Целью данной работы является исследование процессов синтеза и свойств полиэфирамидов на основе $\varepsilon$-капролактама (єКЛ) и $\alpha$-ангеликалактона ( $\alpha$ АЛ).<smiles>CC1=CCC(=O)O1</smiles>
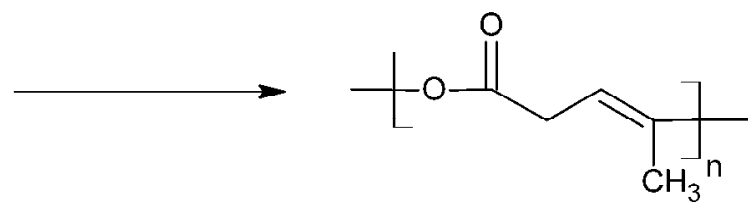

Рис. 1. Схема полимеризации $\alpha$-ангеликалактона

Fig. 1. Scheme of $\alpha$-angelicalactone polymerization 


\section{Экспериментальная часть}

a-Ангеликалактон (Acros Organics, 98 \%) перед использованием подвергали вакуумной перегонке (Р = 12 Торр, Т = 328 K) с последующей дробной перекристаллизацией из расплава $(\mathrm{T}=291 \mathrm{~K})$.

$\varepsilon$-Капролактам (первый сорт, ПО «Азот, г. Кемерово», ГОСТ 7850-2013) очищали перекристаллизацией из толуола.

Тетрагидрофуран (“ч”, ООО «Компонент-реактив») очищали двукратной промывкой насыщенным раствором $\mathrm{NaOH}$, высушивали над твёрдым гидроксидом натрия и перегоняли над металлическим натрием.

Триизопропилат алюминия получали по методике [9].

Полиангеликалактон (ПАЛ) получали анионной полимеризацией в растворе. В колбу емкостью 0,25 л с обратным холодильником помещали 100 мл тщательно осушенного тетрагидрофурана, 0,06 г бензофенона, 0,01 г натрия металлического (мелкие чешуйки). После образования кетила в колбу в токе аргона клали 0,6 г триизопропилата алюминия. Далее в систему загружали 10 г $\alpha$-ангеликалактона. При температуре кипения тетрагидрофурана продолжительность полимеризации 60 мин. Из полученных смол выделяли первую представительную фракцию методом дробного переосаждения этанолом из тетрагидрофурана.

Натриевую соль $\varepsilon$-капролактама (Na-єКЛ) получали сплавлением $\varepsilon$-капролактама с металлическим натрием. В трехгорлую колбу в токе аргона помещали 20 г $\varepsilon$-капролактама, 2 г мелких чешуек металлического натрия. При интенсивном перемешивании колбу плавно нагревали до $90^{\circ} \mathrm{C}$ и выдерживали при этой температуре в течение 30 мин. Далее, не прекращая подачи аргона, реакционную массу охлаждали до комнатной температуры. Полученный продукт перекристаллизовали из толуола, хранили в эксикаторе.

Анионную сополимеризацию в присутствии Na-єКЛ проводили в ампулах и в трехгорлой колбе, снабженной обратным холодильником и мешалкой, в токе аргона. Обогрев осуществляли посредством масляной бани. Расчетное количество єКЛ и Na-єКЛ (1 мол. \% от общей загрузки) расплавляли в колбе при температуре $100{ }^{\circ} \mathrm{C}$, добавляли расчетные количества $\alpha$ АЛ или ПАЛ при постоянном перемешивании. При этой температуре смесь выдерживали в течение 10 мин. Далее отбирали 10-20 проб по 1 мл расплава в подготовленные ампулы. Ампулы заполняли аргоном, запаивали и помещали в масляную баню, поднимали температуру до $180{ }^{\circ} \mathrm{C}$. С момента достижения заданной температуры ампулы из бани вынимали поочередно через заданные промежутки времени. Перемешивание в колбе прекращали с момента перехода реакционной массы в высоковязкое состояние, далее ее выдерживали при заданной температуре в течение 120 мин, после чего охлаждали.

Удаление непрореагировавших мономеров из полученных сополимеров осуществляли методом экстракции хлороформом в течение 8 ч. В том случае, если сополимеры растворялись, их высаживали из соответствующего раствора гексаном, этанолом либо водой.

Молекулярные массы полимеров определяли вискозиметрически в капиллярном вискозиметре.

Физико-механические характеристики (разрушающее напряжение $\sigma_{\mathrm{p}}$, предел текучести $\sigma_{\mathrm{t}}$, относительное удлинение $\varepsilon$ ) определяли в соответствии с ГОСТ 11262-80 при температуре 
испытания $20 \pm 2{ }^{\circ} \mathrm{C}$. Исследуемые образцы толщиной $1 \pm 0,1$ мм вырубали из пластин, полученных методом прямого горячего прессования в соответствии с ГОСТ 12019-66.

Разрушающее напряжение при отрыве (работу адгезии) выявляли методом нормального отрыва в соответствии с ГОСТ 14760-69.

Водопоглощение полимеров устанавливали весовым методом после 24-часовой выдержки полимера в воде.

Исследование способности полученных сополимеров к биодеградации. Образцы полимера размером 5х5х2 мм и образцы тщательно высушенной серой лесной почвы объёмом 15 мл помещали в стеклянные пробирки объемом 45 мл. Пробирки укупоривали силиконовыми пробками с возможностью микрокапельного полива и отбора газовой фазы. Увлажнение системы осуществляли стерильной синтетической минеральной средой Виноградского, приготовленной по ГОСТ Р 54653-2011. Далее пробирки помещали в термостат ТВ-20 и выдерживали при температуре $25^{\circ} \mathrm{C}$ в течение 20 недель. Еженедельно производили отбор проб газовой фазы для определения эмиссии диоксида углерода и метана.

Статистическую оценку токсичности водных вытяжек из почвенных образцов деградации полимеров проводили на многокюветном культиваторе КВМ-05 на культурах инфузорий Stilonichia mytilus (Ehrenberg) и рачков Daphnia magma (Straus).

\section{Результаты и обсуждение}

Выход и скорости образования полимеров. Схема реакции сополимеризации приведена на рис. 2.

В табл. 1 представлены результаты сополимеризации $\varepsilon$-капролактама с $\alpha$-ангеликалактоном и полиангеликалактоном. Выходы сополимеров и блок-сополимеров практически не зависят от того, используется ли $\alpha$ АЛ или ПАЛ в качестве компонента реакционной смеси. Выходы целевых полимеров систематически снижаются с 80 до 40-60 \% при увеличении содержания $\alpha$ АЛ или ПАЛ от нуля до 95 \%. Молекулярные массы получаемых полимеров при этом снижаются примерно вдвое, с 33 до 12-17 тыс.

Кинетические зависимости выходов сополимеров в процессах сополимеризации єКЛ с $\alpha$ АЛ и ПАЛ представлены на рис. 3,4 . Как и в случае с выходами полимеров, скорости сополимеризации систематически снижаются при увеличении доли ангеликалактона и полиангеликалактона в реакционной массе.

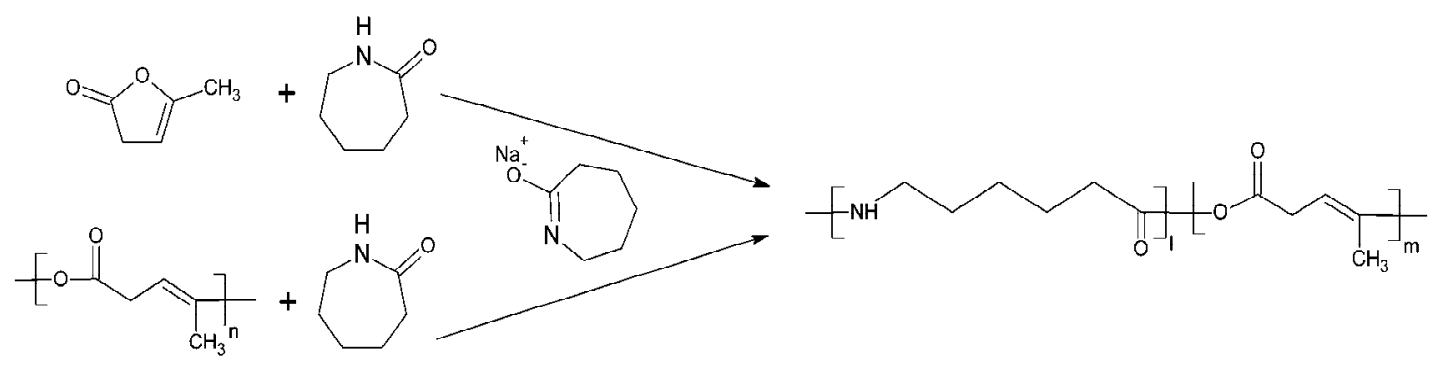

Рис. 2. Схема сополимеризации $\varepsilon$-капролактама с $\alpha$-ангеликалактоном и полиангеликалактоном

Fig. 2. Scheme $\varepsilon$ - caprolactam with $\alpha$-angelicalactone or polyangelicalactone copolymerization

$$
-506-
$$


Таблица 1. Зависимость выхода сополимеров и их молекулярной массы $\left(\mathrm{M}_{\mathrm{W}}\right)$ от состава полимеризуемой смеси.

Table 1. Influence of polymerized mixture composition on the copolymer yields and molecular weight $\left(\mathrm{M}_{\mathrm{W}}\right)$.

\begin{tabular}{|c|c|c|c|c|}
\hline \multirow{2}{*}{$\begin{array}{c}\text { Мольная доля єКЛ, } \\
\%\end{array}$} & \multicolumn{2}{|c|}{ Выход сополимеров, \% ( $\pm 0,4)$} & \multicolumn{2}{c|}{$\mathrm{M}_{\mathrm{W}}, \times 10^{3}( \pm 0,6)$} \\
\cline { 2 - 5 } & $\alpha$ АЛ & ПАЛ & $\alpha$ АЛ & \multicolumn{2}{|c|}{32,8} \\
\hline 100 & \multicolumn{2}{|c|}{80,2} & 30,3 & 31,5 \\
\hline 98 & 76,9 & 79,6 & 30,1 & 30,5 \\
\hline 97 & 74,3 & 79,4 & 27,6 & 30,1 \\
\hline 95 & 76,5 & 78,9 & 28,1 & 28,1 \\
\hline 90 & 75,8 & 77,8 & 25,3 & 23,9 \\
\hline 80 & 71,1 & 76,2 & 19,7 & 21,5 \\
\hline 60 & 70,7 & 69,1 & 16,6 & 18,9 \\
\hline 50 & 66,3 & 60,1 & 13,6 & 12,7 \\
\hline 40 & 65,4 & 61,9 & 17,6 & 15,7 \\
\hline 20 & 61,8 & 62,4 & 12,1 & \\
\hline 5 & 45,4 & 41,4 & & \\
\hline
\end{tabular}

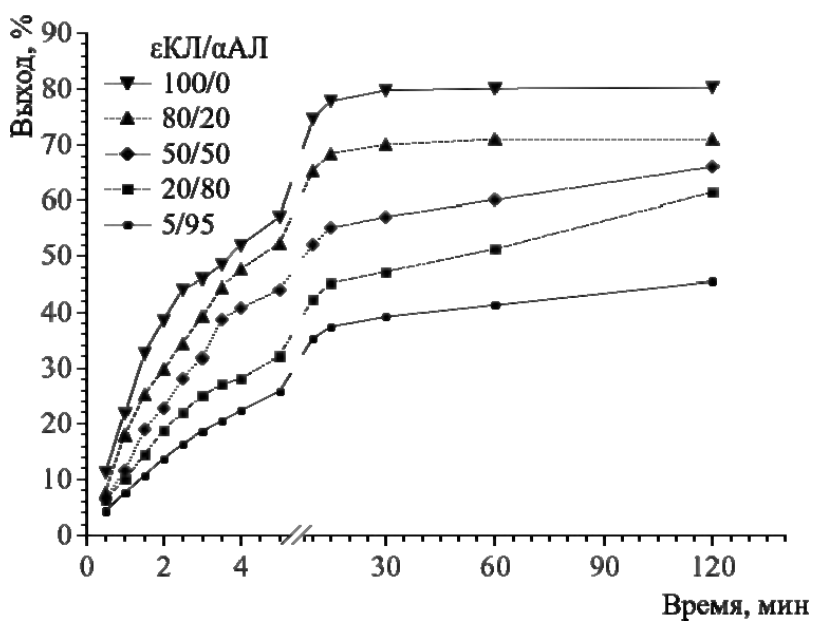

Рис. 3. Кинетические кривые сополимеризации єКЛ/ $\alpha$ АЛ при температуре $180{ }^{\circ} \mathrm{C}$

Fig. 3. The dependences of $\varepsilon$-caprolactam/ $\alpha$-angelicalactone copolymer yield on the reaction time at $180{ }^{\circ} \mathrm{C}$

Полученные результаты показывают, что $\alpha$-ангеликалактон и полиангеликалактон в условиях рассматриваемого процесса являются наименее реакционноспособными компонентами.

Физико-химические и механические свойства полимеров. Изучение растворимости сополимеров показало, что она возрастает с увеличением доли $\alpha$ АЛ или ПАЛ в их структуре и снижается в ряду растворителей:

$$
\text { ДМСО > ДМФА > Хлороформ > Ацетон. }
$$

В ДМСО растворяются все сополимеры (не менее 10 мас. \%), в ацетоне растворимы только сополимеры с содержанием $\alpha$-ангеликалактона или ПАЛ 90 мол. \% и выше.

$$
-507-
$$




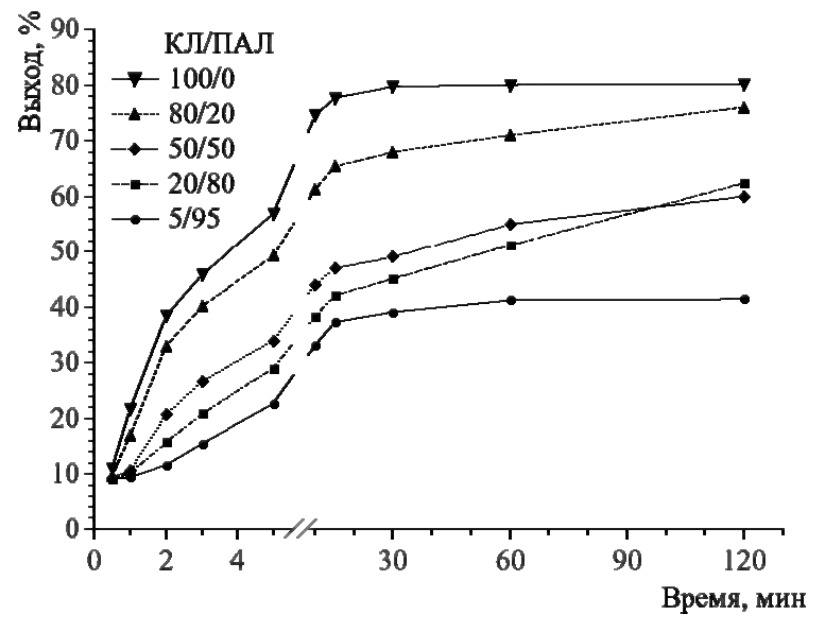

Рис. 4. Кинетические кривые сополимеризации єКЛ/ПАЛ при температуре 180 C

Fig. 4. The dependences of $\varepsilon$-caprolactam/polyangelicalactone copolymer yield on the reaction time at $180{ }^{\circ} \mathrm{C}$

Таблица 2. Физико-механические характеристики блок-сополимеров и сополимеров є-капролактама с $\alpha$ АЛ и ПАЛ

Table 2. Physical and mechanical characteristics of the block copolymers and copolymers of $\varepsilon$-caprolactam, $\alpha$-angelicalactone and polyangelicalactone

\begin{tabular}{|c|c|c|c|c|c|c|c|c|c|c|}
\hline \multirow{2}{*}{$\begin{array}{c}\varepsilon \text {-КЛ, } \\
\text { мол. } \%\end{array}$} & \multicolumn{2}{|c|}{$\sigma_{\mathrm{p}}, \mathrm{MПа}( \pm 4)$} & \multicolumn{2}{|c|}{$\varepsilon, \%( \pm 7 \%)$} & \multicolumn{2}{c|}{$\sigma_{\text {т }}$, МПа $( \pm 4)$} & \multicolumn{2}{c|}{ А, МПа $( \pm 0,8)$} & \multicolumn{2}{c|}{$\mathrm{W}_{\mathrm{o}}, \%( \pm 0,04)$} \\
\cline { 2 - 12 } & ПАЛ & $\alpha$ АЛ & ПАЛ & $\alpha$ АЛ & ПАЛ & $\alpha$ АЛ & ПАЛ & $\alpha$ АЛ & ПАЛ & $\alpha$ АЛ \\
\hline 100 & 50 & 50 & 210 & 210 & 31 & 31 & 0 & 0 & 0,50 & 0,50 \\
\hline 80 & 29 & 29 & 254 & 251,14 & 20 & 20 & 0 & 0 & 0,63 & 0,62 \\
\hline 60 & 25 & 25 & 244 & 240,34 & 25 & 25 & 2,44 & 2,40 & 0,63 & 0,62 \\
\hline 40 & 24 & 23 & 337 & 329,42 & 20 & 20 & 2,66 & 2,60 & 0,80 & 0,78 \\
\hline 20 & 18 & 17 & 318 & 303,69 & 14 & 13 & 3,34 & 3,19 & 1,09 & 1,04 \\
\hline
\end{tabular}

Обозначения: $\rho$ - плотность, $\sigma_{\mathrm{p}}$ - разрушающее напряжение, $\varepsilon$ - удлинение при разрыве, $\sigma_{\mathrm{\tau}}-$ предел текучести, А работа адгезии, $\mathrm{W}_{\mathrm{o}}$ - объёмное водопоглощение за 24 ч.

Физико-механические характеристики изученных сополимеров и блок-сополимеров представлены в табл. 2. При переходе от поликапроамида к полиангеликалактону прочность на разрыв снижается вдвое, предел текучести - в полтора раза. Водопоглощение полученных сополимеров возрастает в пределах от 0,5 до 1,09 \% для сополимеров с ПАЛ и 0,5-1,04 для сополимеров с $\alpha$ АЛ при снижении содержания $\varepsilon$-капролактама. Температура хрупкости получаемых полимеров находится в интервале минус 50 - минус $24{ }^{\circ} \mathrm{C}$ и увеличивается с ростом содержания $\alpha$-ангеликалактона в сополимерах.

Полученные данные о работе адгезии (табл. 2) показывают, что наибольшее значение адгезионной прочности, равное 3,34 МПа, наблюдается у єКЛ/ПАЛ в соотношении 20/80 соответственно. В этом случае разрушение клеевого соединения имело адгезионный характер. С увеличением доли полиэфирной составляющей преобладал когезионный разрыв, что является следствием уменьшения концентрации водородных связей [10]. 
Наибольшей прочностью обладает поли-є-капроамид, а наилучшими эластическими свойствами - полиангеликалактон. Данные характеристики для сополимеров плавно изменяются соответственно составу. Следует отметить, что в области малых содержаний $\alpha$ АЛ и ПАЛ (020 \%) снижение прочностных показателей и рост водопоглощения сополимеров незначительны и находятся на уровне $10 \%$.

Таким образом, в результате сополимеризации єКЛ с ПАЛ образуются кристаллические полимеры. Увеличение содержания ПАЛ или $\alpha$ АЛ в исходной смеси приводит к увеличению гибкости макромолекул сополимеров, что оказывает влияние на физико-механические свойства синтезированных полимеров. Кроме того, наличие в структуре сополимера полиэфирного фрагмента обуславливает проявление адгезионных характеристик. Прочность и значения водопоглощения, напротив, очень зависят от количественного содержания в составе сополиэфирамида звеньев амида, увеличение которого приводило к росту разрушающего напряжения и к снижению гидрофильности полимеров.

Биодеградация полученных сополимеров и блок-сополимеров. Исследование биодеградации образцов блок-сополимеров в серой лесной почве показало, что в течение 20 недель образцы состава (єКЛ/ПАЛ) 98/2, 97/3, 95/5 мольных \% разрушились практически полностью, до мельчайших вкраплений полимера в органическом конгломерате. Поликапролактам, не модифицированный $\alpha$-ангеликалактоном, в этих условиях за время наблюдения биодеградации визуально не поддается. Хроматографический анализ газовой фазы показал наличие метана, этана, ацетальдегида, бутилацетата и других соединений в концентрациях 0,1-6 мг/м³. В эфирных вытяжках обнаружены пальмитиновая, стеариновая и молочная кислоты, глицерин и другие соединения.

Полученные данные по продуцированию средой культивирования двуокиси углерода и метана приведены на рис. 5 и 6 соответственно. В процессе биодеградации блок-сополимеров скорость окисления на порядок превышает скорость метанообразования. Скорости обоих про-

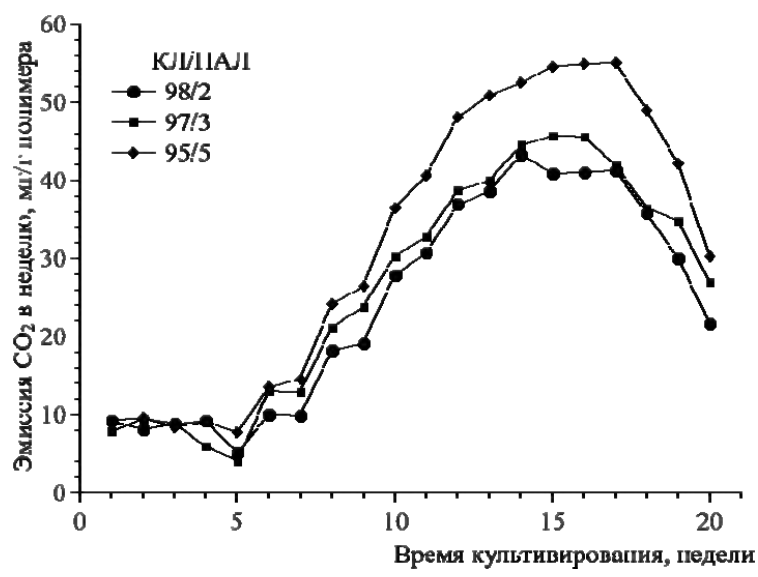

Рис. 5. Эмиссия двуокиси углерода в процессе биодеградации блок-сополимера капролактамполиангеликалактон

Fig. 5. The carbon dioxide emission during biodegradation of block-copolymer of caprolactampolyangelicalacton 


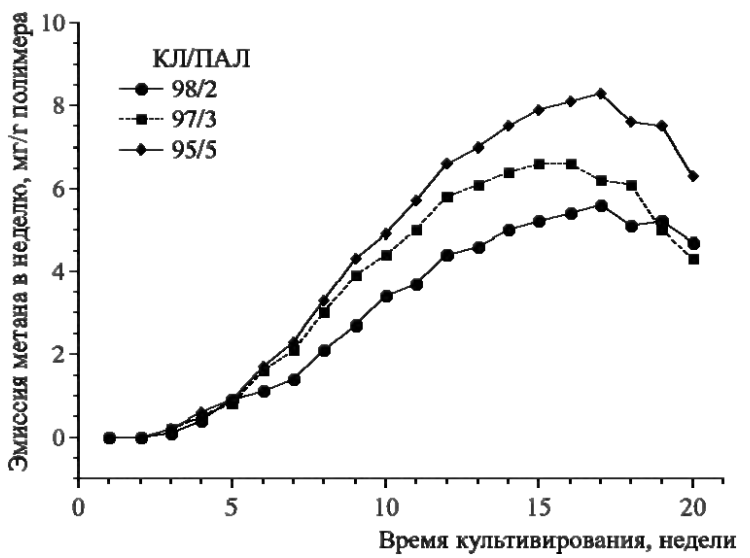

Рис. 6. Эмиссия метана в процессе биодеградации блок-сополимера капролактам-полиангеликалактон

Fig. 6. The methane emission during biodegradation of block-copolymer of caprolactam-polyangelicalacton

Таблица 3. Статистическая оценка токсичности продуктов биодеградации

Table 3. Statistical estimation of the biodegradation product toxicity

\begin{tabular}{|c|c|c|c|c|}
\hline \multirow{2}{*}{$\varepsilon$ КЛ/ПАЛ } & \multicolumn{4}{|c|}{ Тест - объекты (методики оценки) } \\
\cline { 2 - 5 } & Stylonichia mytilus $($ ГОСТ Р 52337-2005) & Daphnia magna (ПНД Ф Т 14.1:2:3:4.12-06) \\
\cline { 2 - 5 } & $\mathrm{N}, \%$ & $\mathrm{n}, \%$ & $\mathrm{~A}, \%$ & $\mathrm{n}, \%$ \\
\hline $98 / 2$ & 97,4 & 6,2 & 4,08 & 7,8 \\
\hline $97 / 3$ & 96,7 & 3,1 & 9,73 & 18,8 \\
\hline $95 / 5$ & 97,6 & 4,7 & 4,7 & 7,8 \\
\hline
\end{tabular}

Обозначения: $\mathrm{N}$ - выживаемость инфузорий при экспозиции 1 ч; А - доля погибших дафний при экспозиции 48 ч; $\mathrm{n}$ - доля повторений с выживаемостью менее $50 \%$.

цессов систематически возрастают при увеличении содержания ПАЛ в блок-сополимерах. Следовательно, наблюдаемая эмиссия газов обусловлена биодеградацией полимеров, а не компонентов почвы, в которой проводили эксперименты. Суммарная эмиссия углекислого газа за 20 недель находится на уровне 40-50 мас. \% в расчете на полимер (рис. 5), что соответствует приблизительно $20 \%$ от стехиометрии полного окисления изученных полимеров в $\mathrm{CO}_{2}$.

Проведен микробиологический анализ образцов разрушения сополимеров. Найдены микроорганизмы родов Phanerochaete, Acremonium, Aspergillius, Clonostachys, Fusarium, Mucor, Penicillum, Thrichoderma, Ulocladium, Umbellopsis.

Проведена статистическая оценка токсичности водных вытяжек продуктов биодеструкции сополиэфирамидов, результаты отражены в табл. 3. Водные вытяжки из массы культивирования сополимеров статистически не показали токсического эффекта. Наблюдались лишь отдельные случаи массовой спонтанной гибели микроорганизмов-индикаторов, вероятно, вследствие попадания токсинов микроорганизмов, участвовавших в биодеструкции.

Полученные результаты показывают, что модификация ПКЛ малыми добавками ангеликалактона и полиангеликалактона (2-10 масс. \%) позволяет получать биодеградируемые сополимеры с физико-механическими свойствами, близкими к немодифицированному ПКЛ. 


\section{Заключение}

1. Впервые проведена анионная сополимеризация $\varepsilon$-капролактама с $\alpha$-ангеликалактоном и полиангеликалактоном, получены серии сополимеров с различным соотношением мономерных звеньев.

2. Установлено, что свойства данных сополимеров зависят от содержания каждого из мономеров в исходной смеси: увеличение доли звеньев $\varepsilon$-капролактама в сополимере приводит к повышению прочностных свойств, к снижению эластических свойств и водопоглощения, увеличение доли звеньев $\alpha$ АЛ(ПАЛ) влечет за собой снижение прочностных свойств, но увеличивает эластичность.

3. Выявлено, что в процессе инкубации образцов сополимеров в почве происходит сукцессия почвенных микроорганизмов на поверхности образцов. Установлено, что под действием ферментных систем микроорганизмов инкубированные образцы сополимеров практически полностью разрушаются в течение 20 недель, а продукты биодеградации статистически не обладают токсическим действием.

\section{Список литературы}

1. Aharoni S. M. n-Nylons: Their Synthesis, Structure, and Properties. Chichester ; New York: J. Wiley \& Sons, 1997. 622 pp.

2. Rydz J., Sikorska W., Kyulavska M., \& Christova D. (2014). Polyester-Based (Bio)degradable Polymers as Environmentally Friendly Materials for Sustainable Development. International Journal of Molecular Sciences 2015. Vol. 16 (1), P. 564-596.

3. Тарабанько, В.Е, Кайгородов К.Л., Соколенко В.А., Черняк М.Ю. Исследование полимеризации альфа-ангеликалактона. Химия растительного сырья 2006. № 2, С. 50-53. [Tarabanko V.E., Kaygorodov K.L., Sokolenko V.A. Chernyak M.Yu. Study of $\alpha$-angelicalactone polymerization. Chemistry of plant raw material 2006. Vol. 2, P. 50-53. (In Russ.)].

4. Tarabanko V.E., Kaygorodov K.L. New biodedradable polymers based on $\alpha$-angelicalactone. Chemistry for Sustainable Development 2010. Vol. 18 (3), P. 321-328.

5. Chen, T., Qin, Z., Qi, Y., Deng, T., Ge, X., Wang, J., Hou, X. Degradable polymers from ring-opening polymerization of $\alpha$-angelica lactone, a five-membered unsaturated lactone. Polymer Chemistry 2011. Vol. 2(5), P. 1190-1194.

6. Tarabanko V. E., Kaygorodov K. L. New Environmentally Benign Polymers Produced by Copolymerization with $\alpha$-Angelicalactone. Macromolecular Symposia 2015. Vol. 354(1), P. 367-373.

7. Kaygorodov K. L., Tarabanko V. E., Tarabanko, N. Thermodynamics of $\alpha$-angelicalactone polymerization. Cogent Chemistry 2018. Vol. 4(1). https: //doi.org/ 10.1080/23312009. 2018. 1443689.

8. Kaygorodov K.L., Tarabanko V.E., Smirnova M.A., Tarabanko N., Malyar Yu.N., Voronchikhin V.D. Emulsion copolymerization of polyangelicalactone with styrene. Journal of Siberian Federal University. Chemistry 2019. Vol. 12(2), P. 261-268.

9. Khosravi M. M. et al. Generalized preparation method and characterization of aluminum isopropoxide, aluminum phenoxide, and aluminum n-hexyloxide. Polyhedron 2013. Vol. 62, P. 18-25.

10. Кинлок Э. Адгезия и адгезивы: Наука и технология. М.: Мир, 1991. 484 с. [Kenlock Е. Adhesion and adhesives: Science and technology. Moskow, Mir, 1991. 484p. (In Russ.)]. 